\title{
Instantaneous field measurements of thermal bridge parameters in ground floor residential room
}

\author{
Martin Ivanov ${ }^{1, *}$ \\ ${ }^{1}$ Technical University - Sofia, FPEPM, Department:" Hydroaerodynamics and Hydraulic Machines", \\ Sofia 1000, Bulgaria
}

\begin{abstract}
The "thermal bridges" are defined as an isolated building's areas, where the construction elements have higher thermal conductivity, compared with the rest of the building envelope. Thus, at cold winter conditions, a significant temperature difference may occur between neighbouring solid and air volumes within the construction. Moreover, it has been documented, that the heating energy demand of a building may be increased with more than $30 \%$, due to the existence of thermal bridges and the increased heat losses from the indoors. Consequently, in the recent years, norms and standards have been developed, for avoiding thermal bridges during the building design process. But still, thermal bridges exist in the indoor environment, especially in older buildings, where no energy efficient measures have been applied. That is why, the presented study focuses on instantaneous field measurements of thermal bridge parameters in real existing ground floor residential room. The thermal bridge propagation is analysed relative to the indoor and outdoor air temperature and relative humidity, as well as with infrared thermal images of the affected external walls. The achieved results give valuable information about the generic conditions for thermal bridge existence, without considering the building envelope properties.
\end{abstract}

\section{Introduction}

In the developed countries worldwide, the building sector is responsible for about $40 \%$ from the total energy demand and consumption. [1] Also, to satisfy these energy needs, the building sector becomes indirectly responsible for about $40 \%$ from the $\mathrm{CO} 2$ and other greenhouse gases emissions in the atmosphere. [2] That is why, different strategies and norms were developed and adopted in the recent years, in order to assure sustainable reduction in the energy consumption in the residence buildings, as well as in the industrial sector. [3]

In the past years, building technologies and structure elements were continuously analysed and improved, in terms of thermal properties and contribution to the energy efficiency of the buildings. [4] All this research helped the countries, especially in Europe,

\footnotetext{
*Corresponding author: $\underline{\mathrm{m} \text { ivanov@tu-sofia.bg }}$
} 
to develop and adopt norms for significant heat loss control. But also, heat transfer paths, like thermal bridges, have been presented in the recent construction regulations. [5] Historically, when the requirements for thermal insulation of the buildings were moderate, the role of thermal bridges over the energy efficiency was considered as minor. But now, it becomes progressively important, especially for the demand for heat flow reduction trough the different well isolated construction elements, with lower thermal transmission values (U-values).

However, while the overall heat losses from the newly developed buildings have been decreased, it has been documented that, the portion of heat losses due to the thermal bridges has been increased. This is especially valid for the point thermal bridges, issuing from different modern façade technologies, which may contribute to more than $25 \%$ of the heat flows through the building envelope. [5] But, the impact of the linear thermal bridges on the heating energy need of the buildings may become even higher - above $30 \%$. [6]

Another very important aspect of the thermal bridges is their impact over the indoor environment, especially in residential occupied spaces. The cold spots of the thermal bridges, particularly in winter conditions, may be a prerequisite for humidity related problems in the premises. The accumulated moisture over the thermal bridge surface, may support mold growth, which has direct affect over the occupants' health, productivity and performance.

In thermal bridge analyses, the building structure is considered as the most important parameter, for the heat flow distribution. [7, 8, 9] But, for the generic conditions for thermal bridge existence, the indoor and outdoor atmospheric conditions, are also very important factors, and may be analysed without considering the building structure. Sometimes, the characteristics of the building envelope structure are not available, especially in older or historic buildings. But, thermal bridges may still exist in these premises, and there is a necessity for mitigation measures of the corresponding negative effects.

That is why, a substantial need exists, for measurement data and analyses of the generic conditions for thermal bridge existence, especially for boundary and initial conditions in the numerical modelling of the related phenomena. This is the main purpose of the suggested research in this paper. The described experimental measurements are oriented in the field of non-ventilated residence rooms, which have the highest impact over the today's society. Also, special attention is carried on the case of ground floor residential rooms. In these rooms, the thermal bridge development potential is significantly higher, due to the direct contact with the solid ground.

\section{Objectives of the study}

The global objective of the presented study is to obtain and analyse the generic conditions for thermal bridge existence in ground floor residential room, by instantaneous field measurements of the thermal bridge parameters and the indoor and outdoor environmental conditions.

\section{Methods of the study}

The main approach in the presented study consists of field experimental measurements of the microclimate parameters, in real existing ground floor residential room, with confirmed thermal bridge in the floor area. The thermal bridge zone is confirmed by preliminary taken thermal images of the outer walls. The instantaneously measured parameters include: room air temperature, wall surface temperature, relative humidity, $\mathrm{CO} 2$ concentration, outdoor air temperature and outdoor relative humidity. Also, infrared images 
of the thermal bridge area were taken in during the measurements, each morning and evening, in order to visualize the bridge propagation in the occupied space. The room is occupied, and the measurements were taken under uncontrolled occupant behaviour, which corresponds to the real room use. The effect of the occupant behaviour, over the generic conditions for the thermal bridge existence, will be studied later.

The measurements were taken in the winter period, with duration of 3 days and 3 nights, which corresponds to a short-term experiment. The winter period was selected, because the generic conditions of the thermal bridge existence are much better established and captured in the heating period of the year. Also, a weekend period was selected for the measurements - from 22:00h at 15. February 2019 (Friday), till 22:00h at 18. February 2019 (Monday). The reason was that during the weekend period, the selected residential room is mostly occupied, and the impact of the occupants over the thermal bridge propagation could be studied.

The physical measurements of the environmental parameters are performed by advanced wireless instrumentation (HOBO data loggers, made by ONSET Company), allowing recording of the changes in air temperature, relative humidity and carbon dioxide concentration in the room. The records were taken for each minute in each measurement point, for the entire duration period - 3 days and 4 nights. In addition, an FLIR C3 infrared thermal camera is used, to capture the surface temperature of the inner side of the outer walls in the thermal bridge area.

All obtained results are descriptively analysed and presented in terms of tables and graphics. It is considered that, this analysis gives valuable information about the generic conditions for thermal bridge existence, without considering the building envelope properties. The data will be used later, for initial and boundary conditions for the development of CFD (Computational Fluid Dynamics) based numerical model. This model will be able to predict the thermal bridge distribution in the affected occupied zones, but also a conjugated heat transfer could be included, in order to investigate the complex effect of the thermal bridge over the building structure itself.

\section{Experimental set-up and instrumentation}

On Fig. 1 are presented the ground floor residential room layout and the corresponding measurement points. The room is part of auxiliary guest house in a property, situated in the western part of Sofia, Bulgaria. The orientation of the room is South, and the window is situated in South. The floor area is $16 \mathrm{~m}^{2}$, and the room height is $2.80 \mathrm{~m}$, which corresponds to approximately $44.80 \mathrm{~m}^{3}$ of free space. This room is basically used for a sleeping room and is normally occupied by two adult persons. The heating of the room is provided by a radiator, situated under the window, which is part of central heating system of the auxiliary building. During the experiments, the radiator was working constantly, to maintain the comfortable $20{ }^{\circ} \mathrm{C}-21{ }^{\circ} \mathrm{C}$ in the room, and the heating set-point was not modified additionally.

As indicated on the figure, the confirmed thermal bridge zone is on the floor area in the corner, between the two external walls. Considering the building structure, it should be noted that both walls are well insulated, but the ground concrete floor is not. Also, in the thermal bridge area, there is a concrete support column, supporting the concrete roof. This structural layout is a prerequisite for thermal bridge existence itself, but still the generic conditions need to be additionally examined.

The measurement devices were divided in three separate systems, the position of which are indicated on Fig. 1. System 1 and System 2 consist of one HOBO data logger in combination with Telaire $7001 \quad \mathrm{CO}_{2}$ sensors. These devices allow instantaneous measurements of air temperature, relative humidity and $\mathrm{CO}_{2}$ concentration. The 
measurement points were selected to be away of the breathing zones of the occupants and away of the walls, in that way to cover the established measurement standards. The elevation from the ground was approximately one meter.

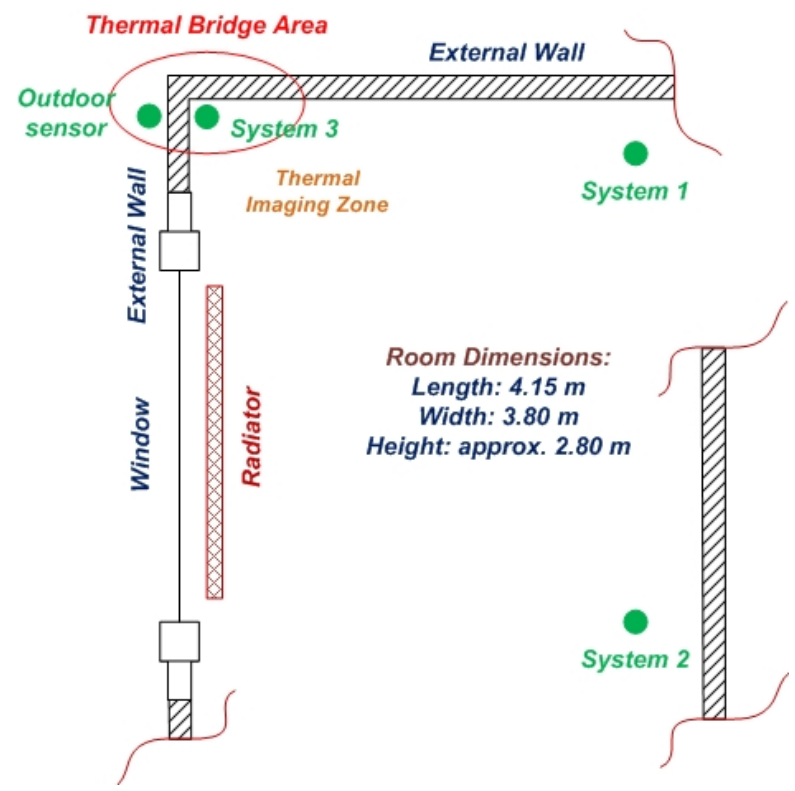

Fig. 1. Experimental room layout

System 3 consist of only one HOBO data logger for measurement of air temperature and relative humidity. This sensor was installed on the floor of the room, as close as possible to the external wall surface, in the thermal bridge zone. In that way System 3 measures the closest possible indoor parameters, affected by the thermal bridge existence. As it was mentioned, this is the zone for the thermal images as well. It should be noted, that when the thermal pictures were taken, the System 3 sensor was slightly removed from the place, for less than a minute, and then returned into place.

On the opposite side of System 3, over the outside wall surface, was placed the Outdoor sensor. This sensor provided the outdoor atmospheric conditions in terms of air temperature and air relative humidity. Thermal images in this zone were also taken, during the experimental period.

As it was mentioned, the room was occupied by two adults, during the experiments. Also, the period was attentively selected to be during the weekend, in order to stimulate the thermal load in the room. However, the occupant behaviour towards the indoor environment parameters, was not modified by any means. This will help in the understanding of the thermal bridge generic conditions.

\section{Results and discussion}

All obtained measurement data is processed and analysed. In this paper, only the results for the measured temperatures and relative humidity will be presented. It is considered that these values justify the instantaneous generic conditions for the thermal bridge existence in the ground floor residential room. The results are presented in terms of figures and tables, describing the temperatures and relative humidity distribution, within the entire experimental period. 
The outdoor atmospheric conditions, in terms of air temperature and relative humidity, are presented on Fig. 2, for the entire measurement period. The summarized values, as well as the standard deviation are presented in Table 1 . The minimum value of the measured temperature is $-1.07{ }^{\circ} \mathrm{C}$. The maximum measured value is $22.94{ }^{\circ} \mathrm{C}$, which is not normal for February in Bulgarian climate, according to the national statistics. The average measured temperature is $5.88{ }^{\circ} \mathrm{C}$ for the entire experimental period, which is also higher than the normal statistical values for that month.

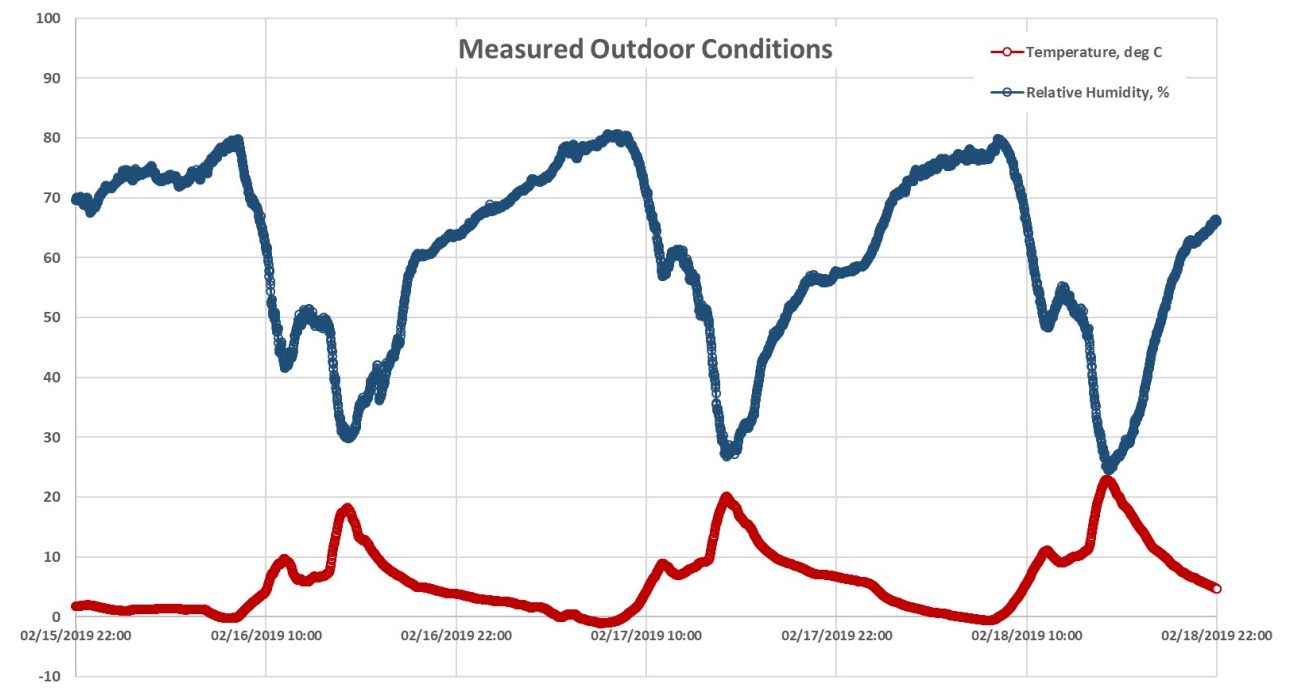

Fig. 2. Measured outdoor atmospheric conditions

Table 1. Summarized outdoor atmospheric conditions

\begin{tabular}{|c|c|c|c|c|}
\hline Outdoor condition & $\min$ & $\max$ & average & SD \\
\hline Temperature, ${ }^{\circ} \mathrm{C}$ & -1.07 & 22.94 & 5.88 & 5.46 \\
\hline Relative Humidity, \% & 24.55 & 87.92 & 60.46 & 15.03 \\
\hline
\end{tabular}

The measured values of the relative humidity are as follows: minimum value is $24.55 \%$, the maximum value is $87.92 \%$, and the corresponding average value is $60.46 \%$. The deviations of the relative humidity values clearly correspond with the increase and the decrease of the atmospheric air temperature. Both deviations happen distinctively during the day and night periods, as is clearly shown on Fig. 2. During the night period, the atmospheric air temperature is lower, and the relative humidity is higher. Obviously, these deviations will strongly affect the heat transfer trough the wall, in the thermal bridge area.

The indoor environment air temperature and relative humidity are presented on Fig. 3 and Fig. 4, for the measurement Systems 1 and 2. They are presented in different graphs, for more clear visualization of the measured values' distribution. The summarized values from the corresponding measurement points are presented in Tables 2 and 3, respectively after each graph.

The minimum value of the measured indoor temperature for System 1 is $18.39^{\circ} \mathrm{C}$. The maximum measured value is $21.32{ }^{\circ} \mathrm{C}$, and the average measured temperature is $20.14{ }^{\circ} \mathrm{C}$, with standard deviation of only $0.62{ }^{\circ} \mathrm{C}$ for the entire experimental period. The measured 
minimum value of the indoor relative humidity is $33.53 \%$. The maximum value is $59.22 \%$, and the corresponding average value is $47.29 \%$.

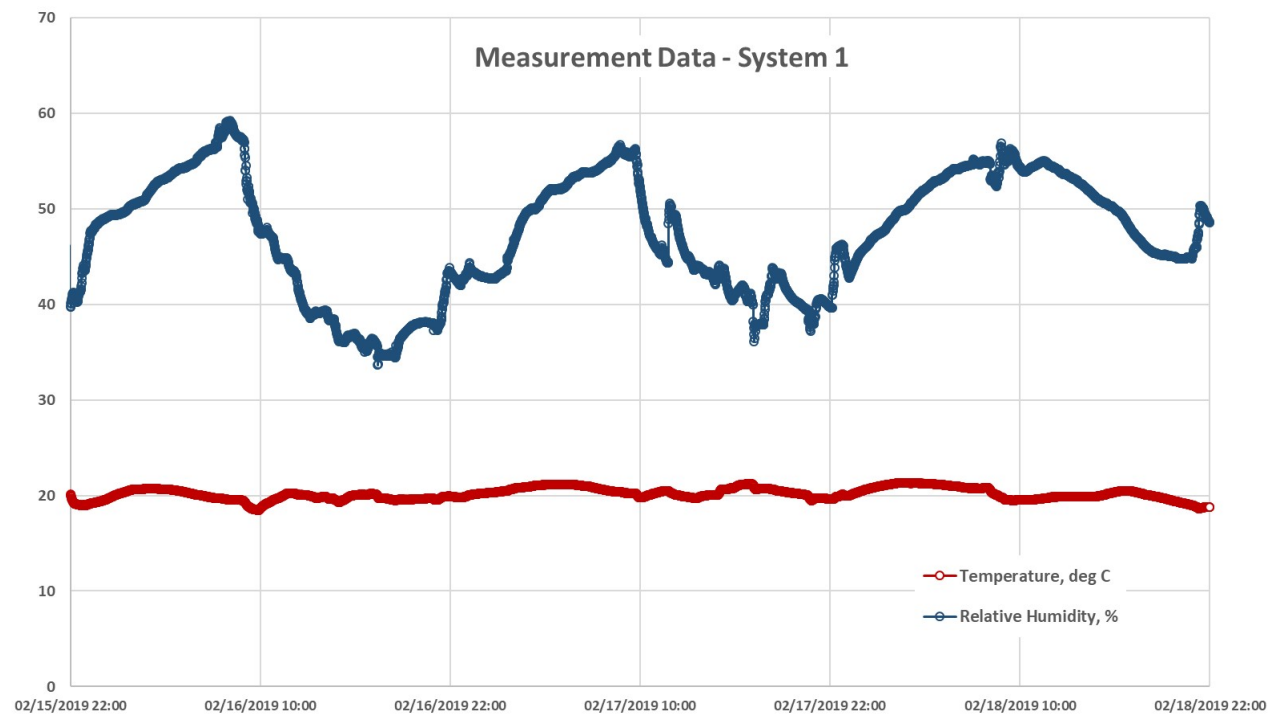

Fig. 3. Measured indoor data for System 1

Table 2. Summarized indoor data for System 1

\begin{tabular}{|c|c|c|c|c|}
\hline Indoor data, System 1 & $\min$ & $\mathbf{m a x}$ & average & SD \\
\hline Temperature, ${ }^{\circ} \mathrm{C}$ & 18.39 & 21.32 & 20.14 & 0.62 \\
\hline Relative Humidity, \% & 33.53 & 59.22 & 47.29 & 6.18 \\
\hline
\end{tabular}

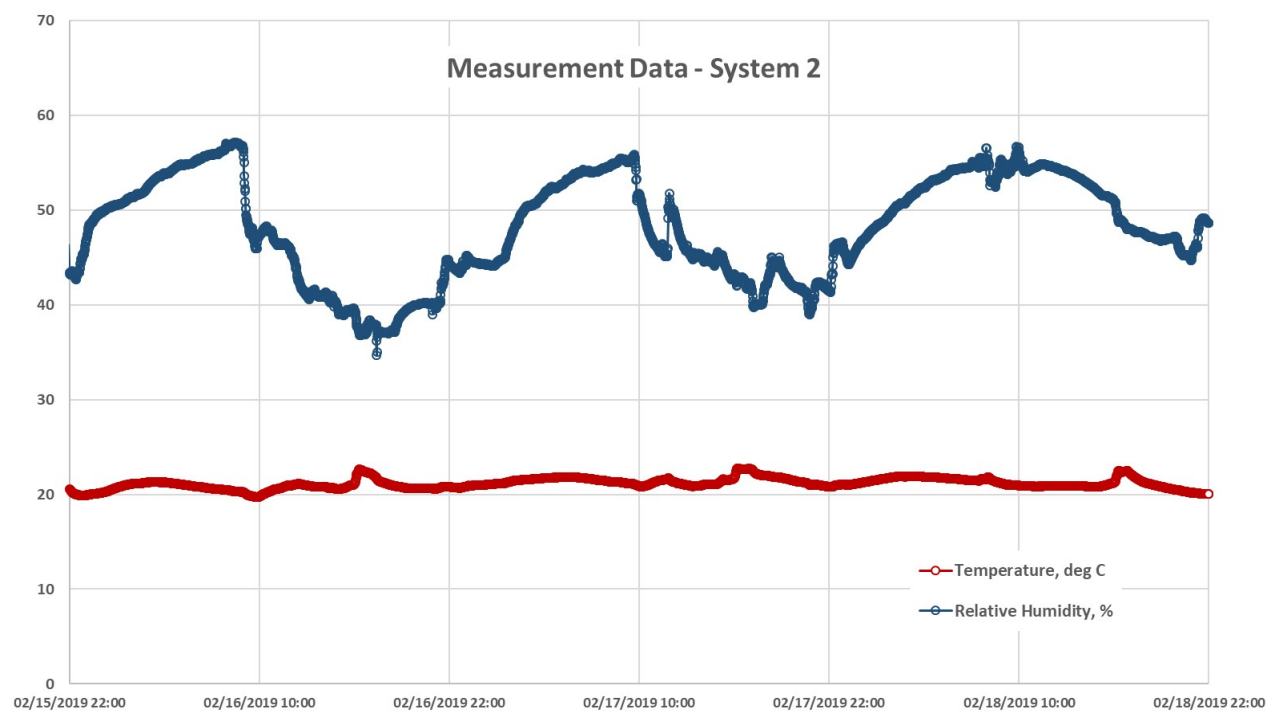

Fig. 4. Measured indoor data for System 2 
Table 3. Summarized indoor data for System 2

\begin{tabular}{|c|c|c|c|c|}
\hline Indoor data, System 2 & $\min$ & $\max$ & average & SD \\
\hline Temperature, ${ }^{\circ} \mathrm{C}$ & 18.58 & 22.73 & 21.11 & 0.60 \\
\hline Relative Humidity, \% & 34.68 & 57.14 & 48.14 & 5.39 \\
\hline
\end{tabular}

The corresponding minimum value of the measured indoor temperature for System 2 is $18.58{ }^{\circ} \mathrm{C}$. The maximum measured value is $22.73{ }^{\circ} \mathrm{C}$, and the average measured temperature is $21.11{ }^{\circ} \mathrm{C}$, with standard deviation again of only $0.60{ }^{\circ} \mathrm{C}$ for the entire experimental period. The measured minimum value of the indoor relative humidity, according to System 2 is $34.68 \%$. The maximum value is $57.14 \%$, and the corresponding average value is $48.14 \%$.

The summarized data for the two measurement systems shows relatively high degree of homogeneity in the indoor air temperature and relative humidity distribution in the experimental room. System 2 is closer to the inner wall and closer to the door of the room, which leads to adjacent indoor spaces. It is away from the thermal bridge zone, and that is why it shows relatively higher average values of the measured parameters. The proximity of System 1 to the thermal bridge area, explains the lower value of the average measured temperature. But, the difference of the relative humidity is mostly due to the non-perfect mixing of the room air and due to a decreased aeration rate in relatively large periods of time. The analyses of the $\mathrm{CO}_{2}$ concentration measurements will give additional explanation of this effect and will be presented in another supplementary paper. The metabolic $\mathrm{CO}_{2}$ concentration is a faster indicator for the aeration rate in the room, compared with the temperature and relative humidity, especially when there is a heating device installed. The longer periods with high $\mathrm{CO}_{2}$ concentration, are indicator for low aeration or infiltration rate in the room. However, the deviations between the results in the two measurement points are considerably small, and the values itself are in the comfortable range for the indoor environment requirements for the winter season. This means that, the thermal bridge areas will be more accurately defined, and the generic conditions will be more precisely established.

The measured values of the air temperature and relative humidity in the thermal bridge zone, System 3, are presented on Fig. 5 and summarized in Table 4. The minimum value of the measured air temperature for System 3 is $11.93{ }^{\circ} \mathrm{C}$. The maximum measured value is $20.29{ }^{\circ} \mathrm{C}$, and the average measured temperature is $13.89{ }^{\circ} \mathrm{C}$, with standard deviation of $1.06{ }^{\circ} \mathrm{C}$ for the entire experimental period. The measured minimum value of the relative humidity, in the thermal bridge zone is $39.67 \%$. The maximum value is $83.77 \%$, and the corresponding average value is $67.56 \%$.

The obtained results for the thermal bridge zone clearly show significantly lower values of the air temperature and significantly higher values of the relative humidity, compared with the rest of the residence room. The graphics on Fig. 5 shows the predisposition of constant heat losses through the thermal bridge zone. The higher values of the relative humidity in this zone indicates the possibility for moisture related problems on the surface of the external wall.

These effects are confirmed by the thermal imaging results, presented in Table 5 . The images show the surface temperature in the thermal bridge zone, captured each morning and each evening, during the experimental period. The camera marker is set to show the minimum measured temperature in the focus area. Thermal images of the outside wall conditions were also taken at the same time but will not be presented in this paper. The 
results here are concentrated on the impact of the thermal bridge over the indoor environment.

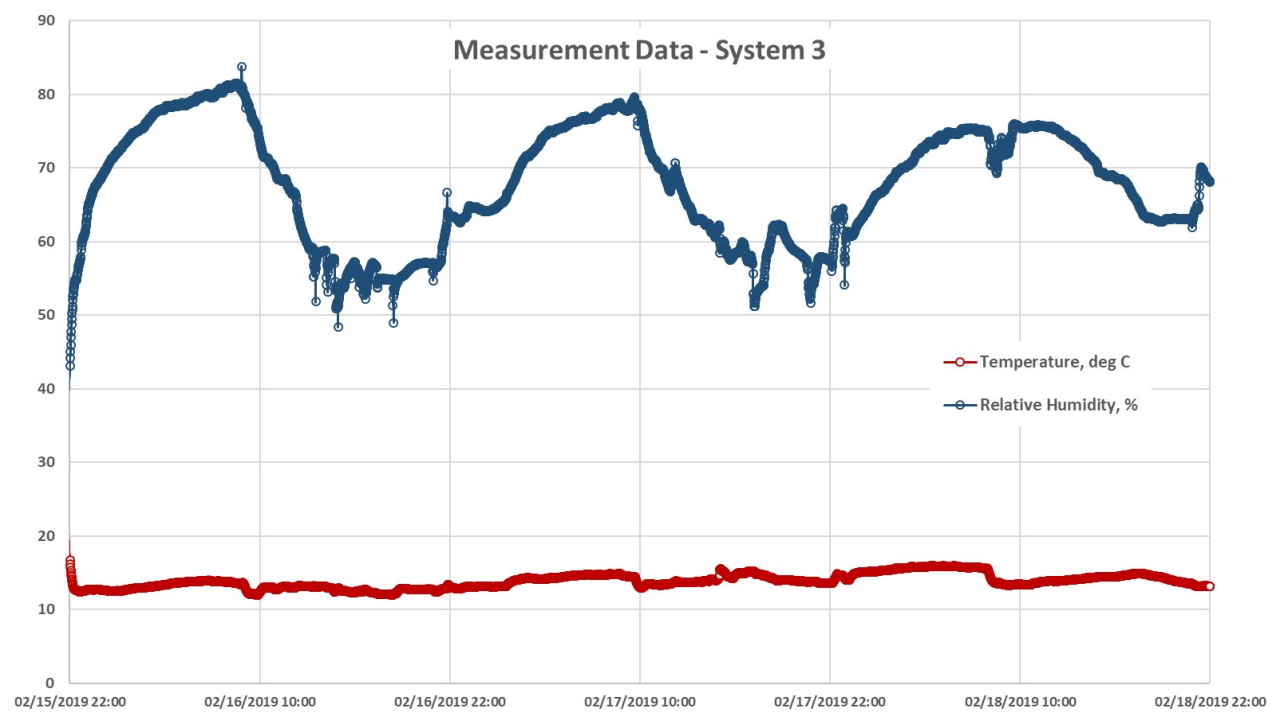

Fig. 5. Measured indoor data for System 3

Table 4. Summarized indoor data for System 3

\begin{tabular}{|c|c|c|c|c|}
\hline Indoor data, System 3 & min & $\mathbf{m a x}$ & average & SD \\
\hline Temperature, ${ }^{\circ} \mathrm{C}$ & 11.93 & 20.29 & 13.89 & 1.06 \\
\hline Relative Humidity, \% & 39.67 & 83.77 & 67.56 & 8.13 \\
\hline
\end{tabular}

Table 5. Thermal images from the field experiments

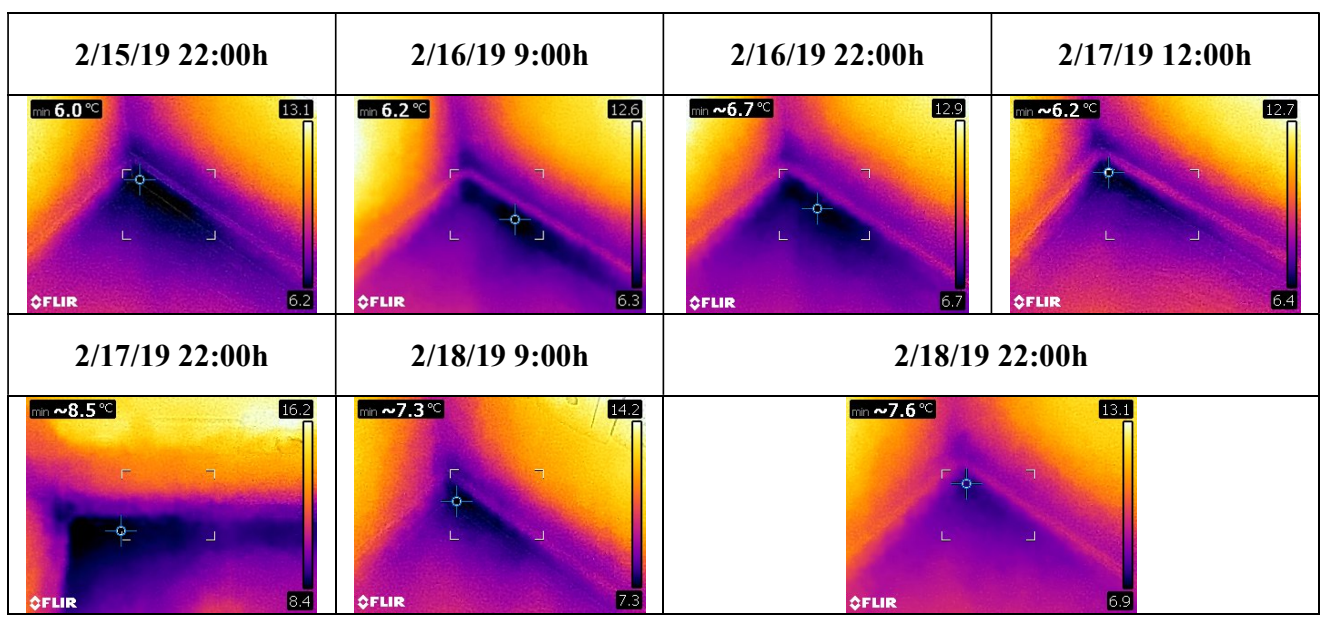


For further analyses, this thermal imaging data is compared with the measured values of the air temperature form System 3 and it is presented on Fig. 7. As it can be seen, the measured surface temperature values are significantly lower than the one, measured with the logger. This could be expected, because the logger measures the air temperature in very close proximity with the thermal bridge zone, compared to the direct surface temperature, captured by the thermal camera.

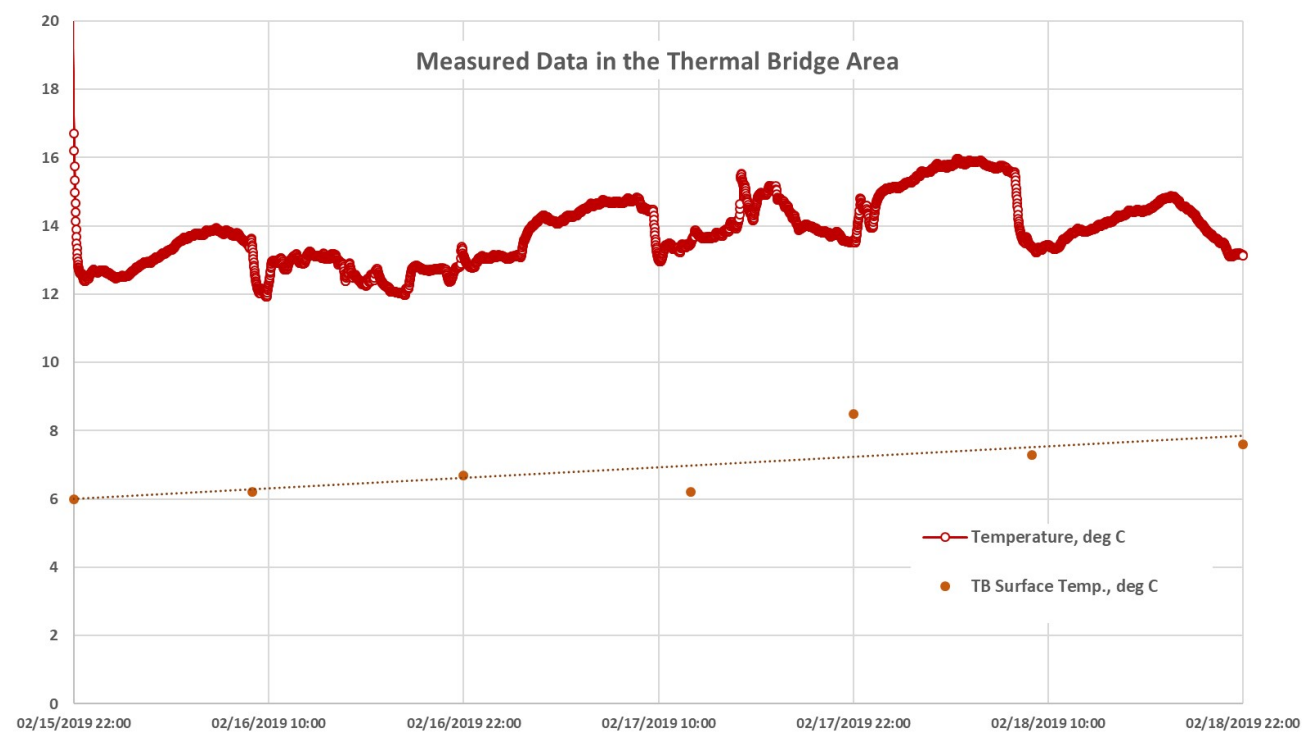

Fig. 7. Comparison of the measured data in the thermal bridge area

Obviously, the thermal camera may account better for the heat loss trough the solid surface of the wall. However, for precise modelling of the conjugated heat transfer in such experimental set up, the air temperature around the solid cold surface, is also important generic parameter for the thermal bridge existence. Collecting such boundary condition experimental data, seems to be innovative approach in the existing knowledge on thermal bridges and their impact on the indoor air quality.

Additional processing of the obtained data will also be accomplished. The next step will be to analyse the dew point temperature distribution in the occupied residential space, which will be an indicator for humidity related problems, over the thermal bridge surface area. Mitigation measures could also be suggested, in order to minimize the thermal bridge propagation zone. Depending on the further analyses, these measures may include not only structural isolation, but for example slight increase of the room temperature, or increase of the aeration rate, for lowering the humidity related problems in the thermal bridge area.

\section{Conclusions}

Instantaneous field measurements of thermal bridge parameters, in ground floor residential room, were performed in the presented study. The analyses of the results showed the generic conditions for the thermal bridge existence, without considering the building structure.

The achieved measurement results showed relatively high degree of homogeneity in the indoor air temperature and relative humidity distribution in the selected experimental room. 
As it was occupied by two persons, the values of the temperature and relative humidity are in the comfortable range for the indoor environment requirements in the winter season.

However, the results showed that the room have distinctively confirmed thermal bridge zone, situated in the floor area between the two outer walls. The obtained results near the thermal bridge clearly showed lower values of the air temperature and higher values of the relative humidity, compared with the rest of the residence room.

This effect was confirmed by the thermal images and is considered as predisposition of constant heat losses through the thermal bridge area. The higher values of the relative humidity in this zone indicates the possibility for moisture related problems on the surface of the external wall.

The presented experimental results provide important information about the mechanism of interaction of the different microclimate parameters, relative to the generic conditions for thermal bridge existence. The data obtained will be used to create a numerical model, which might predict the heat losses as well as the appearance of humidity related problems in the premises.

\section{Acknowledgements}

The presented study is supported by the National Science Fund at the Ministry of Education and Science of Bulgaria, under the activities of: "Competition for financial support for projects of junior basic researchers and postdocs - 2018”, with Contract № КП-06-M27/4, entitled: "Numerical assessment of effective measures for prevention of moisture accumulation on external walls with thermal bridge, in residential rooms without organized ventilation".

\section{References}

[1] Eurostat: "Tables, Graphs and Maps Interface”, https://ec.europa.eu/eurostat, (Accessed April 2019)

[2] International Energy Agency, “Modernising Building Energy Codes”, (2013)

[3] International Energy Agency, "Transition to Sustainable Buildings: Strategies and Opportunities to 2050)", (2013)

[4] T. Theodosiou, K. Tsikaloudaki, S. Tsoka, P. Chastas, "Thermal bridging problems on advanced cladding systems and smart building facades”, J. Clean. Prod., 214, 62-69 Elsevier (2019)

[5] A. Papadopoulos, "Forty years of regulations on the thermal performance of the building envelope in Europe: achievements, perspectives and challenges", Energy Build. 127. https://doi.org/10.1016/j.enbuild.2016.06.051, (2016)

[6] H. Erhorn-Kluttig, H. Erhorn, "Impact of thermal bridges on the energy performance of buildings", Paper P148 of the EPBD Buildings Platform, (2009)

[7] ISO 10211, "Thermal Bridges in Building Construction - Heat Flows and Surface Temperatures. Detailed calculations", International Organization for Standardization, (2017)

[8] ISO 10456, "Building Materials and Products, Hygrothermal Properties, Tabulated Design Values and Procedures for Determining Declared and Design Thermal Values", International Organization for Standardization, (2007)

[9] EN ISO 6946, "Building Components and Building Elements - Thermal Resistance and Thermal Transmittance - Calculation Method", International Organization for Standardization, (2012) 